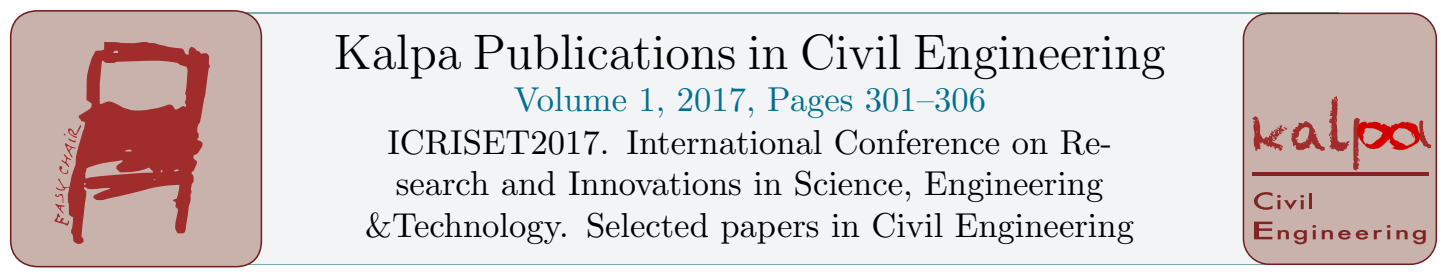

\title{
Estimation of Suspended Sediment Concentration in Lined Canal
}

\author{
Rahul S. Patel ${ }^{1}$, Dr. S. M. Yadav ${ }^{2}$ and Sahita I. Waikhom ${ }^{3}$ \\ ${ }^{1}$ Department of Civil Engineering, Dr. S \& S. S. Ghandhy GEC Surat, Gujarat, India \\ ${ }^{2}$ Department of Civil Engineering, S. V. National Institute of Technology Surat, Gujarat, India \\ ${ }^{3}$ Department of Civil Engineering, Dr. S \& S. S. Ghandhy GEC Surat, Gujarat, India \\ rahulspatel46@gmail.com, shivnam27@gmail.com, siwgecs@gmail.com
}

\begin{abstract}
This Paper presents estimation of suspended sediment concentration in lined canal. The suspended sediment concentration measurement is been carried out for different discharges including minimum and maximum discharges at one section of Kakrapar Left Bank Main Canal. The bridge method has been used for the collection of suspended sediment water sample. For this purpose, a section selected at Tarsada Highway Bridge which is across the main canal. The total numbers of four; in-site observations were made; many samples of water sediment mixture were taken from the canal section during each observation, these samples were filtered through filter paper and the average suspended sediment concentration recorded. The suspended sediment transport rate was calculated from the observed sediment concentration. The suspended sediment water samples were collected using Punjab bottle sampler. Also for each observation, the water velocity was measured laterally at different point on crosssection by using current meter and the average velocity was computed. The graphs of suspended sediment concentration for different discharges were plotted.
\end{abstract}

Keywords- Suspended sediment, Sediment concentration, Sediment transport rate, Velocity distribution, Lined canal

\section{Introduction}

The movement of suspended sediment transport in an irrigation canal is of fundamental interest in understanding its transport phenomena [3]. Suspended sediment load generally occupies a major portion of the total load in an irrigation canal and sometimes it becomes predominant. The movement of suspended sediment has a wide variety of results in an artificial channel, which includes the reduction in capacity of irrigation canal due to silting [6]. The most appropriate method for the determination of suspended sediment discharge in channels is through the direct measurement of the 
flow rate together with measurement of suspended sediment concentration for a specific time period. The product of flow rate and suspended sediment concentration gives the suspended sediment discharge. The velocities and suspended sediment concentration measurement in the channels should be taken in the whole flow-cross section, from edge to edge of the channel cross section i.e., from the left side to the right side of the channel, from the base to the free water surface of the stream and also along the length of the channel. Generally, Samplings of suspended sediment in natural rivers or in channels are carried out not in accordance with the suitable sampling standards due to some constraints usually found during the field work. As the constraints found in the field, suspended sediment water samples are majorly taken only at appropriate positions in the channels which are easily accessible and/or can be measured, and frequently do not follow the standard sampling technique; for example if the collection of suspended sediment water sample is been done (and measure the flow rate) only at the edge of the channels, and not on the entire cross sectional flow of the channel; the collection of suspended sediment water sample is also often carried out only near the free water surface and not up to the entire depth of the flow. This will lead to inaccuracies in determining the flow velocity, suspended sediment concentration and suspended sediment transport rate in channels [7].

The two methods for the collection of suspended sediment water sample from the river are the Bridge method and Boat Method (Which is explained by Central Water Commission). The Gauging sites of central water commission in the India are using Bridge method for the collection of water sample from the river for estimation of suspended sediment concentration. The same methods for measurement are applied for the canal of single cross-section in the present study. The objective of the study is to estimate the suspended sediment concentration in lined canal.

\section{Study Area}

The data required for the estimation of suspended sediment concentration was collected in single section of Kakrapar left bank main canal. The Kakrapar Left Bank Main Canal was off-take from the Rataniya Head Regulator (H.R). It is located at 21013'41.52" North and $73^{\circ} 19^{\prime} 18.25^{\prime \prime}$ East of Rataniya, a village in Gujarat state of India. The selected section on this lined canal is at Tarsada highway bridge across the canal located at $21^{0} 13^{\prime} 49.43^{\prime \prime}$ North and $73^{0} 19^{\prime} 34.70^{\prime \prime}$ East, in Varjakhan village. The figure 1 shows the location of the selected canal cross-section.

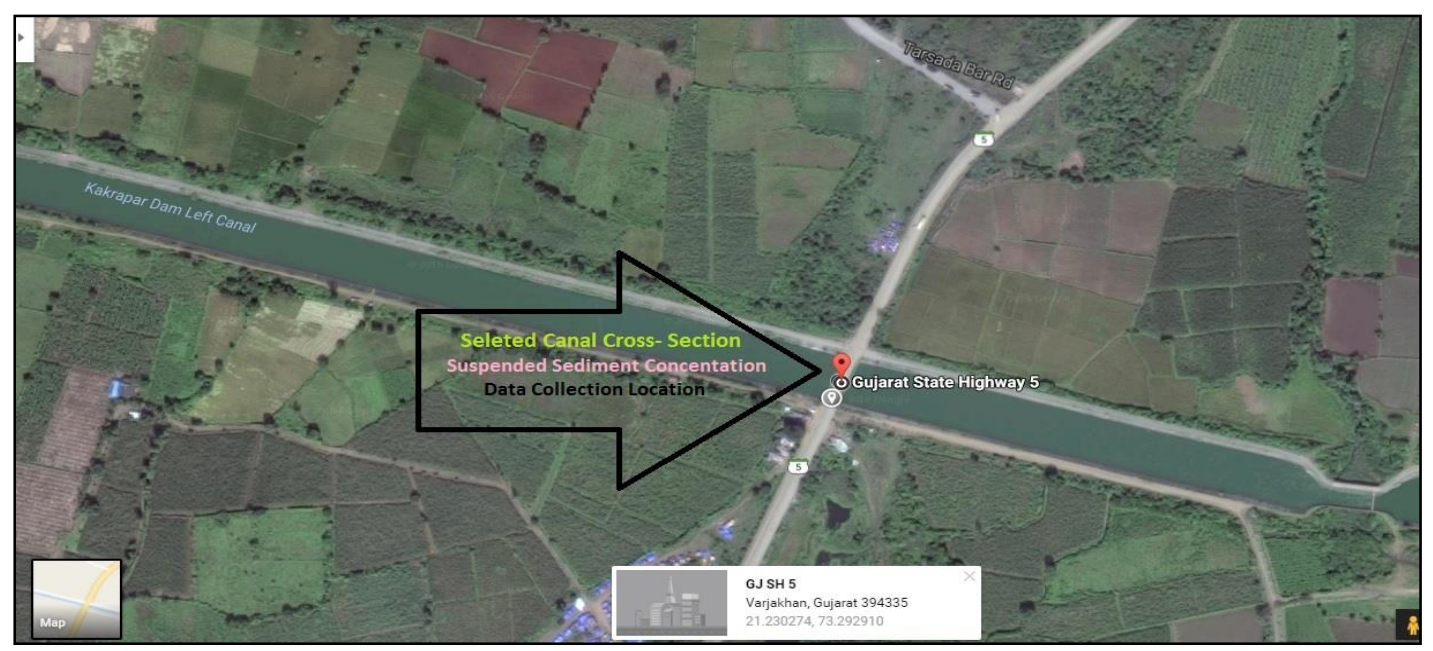

Figure 1: Location of Selected Canal Cross-Section 


\section{Data Collection}

\subsection{Field Data}

The set of data for four in-site observations includes the total number of 20 data records; each record contains the water depth, point velocity, average water discharge, and average suspended sediment concentration along with the calculation of the suspended sediment transport rate. Sampling has been performed at the selected canal cross-section of five appropriate different points (or verticals) for four different discharge conditions including the maximum and minimum discharge condition.

\subsection{Collection of Suspended Sediment Water Sample}

The Punjab bottle sampler was used for the collection of suspended sediment water sample in the canal. The Punjab bottle sampler is shown in figure 2. In this study Bridge method was used for the collection of suspended sediment water sample at selected cross sections. Five Samples were collected at five selected lateral points from the left bank reference point on canal cross-section and mixed the samples during each observation to measure the average sediment concentration as well as the suspended sediment transport rate. The distance of each lateral point from the left bank reference point on the bridge deck slab is mention in second column of table 2.

For the collection of water sample, first the bridge section is divided in to the suitably spaced segment and selects the sampling station across the bridge section. The depth is measured by hanging from bridge and placing the fish weight of $15 \mathrm{~kg}$ at the bottom of the channel bed. The depth of water in canal is determined and at $60 \%$ depth from the free water surface sampling is done. The Punjab bottle sampler is allowed to move freely from the pulley and up to the sampling depth (60\% of water depth). As the sampler reached at sampling depth, the lever arm of the sampler is allowed to pull in upward direction so that the rubber cork of the bottle is open and the water containing the suspended sediment is filled up in to the bottle. The sampler is allowed to fill the water for approximately of about 30 seconds. The collection of water sample is shown in figure 3. By the similar method the suspended sediment water samples are collected for all observation. The collected suspended sediment water samples at five selected lateral points are mixed together and the process for analysis of water sample in the laboratory is carried out.

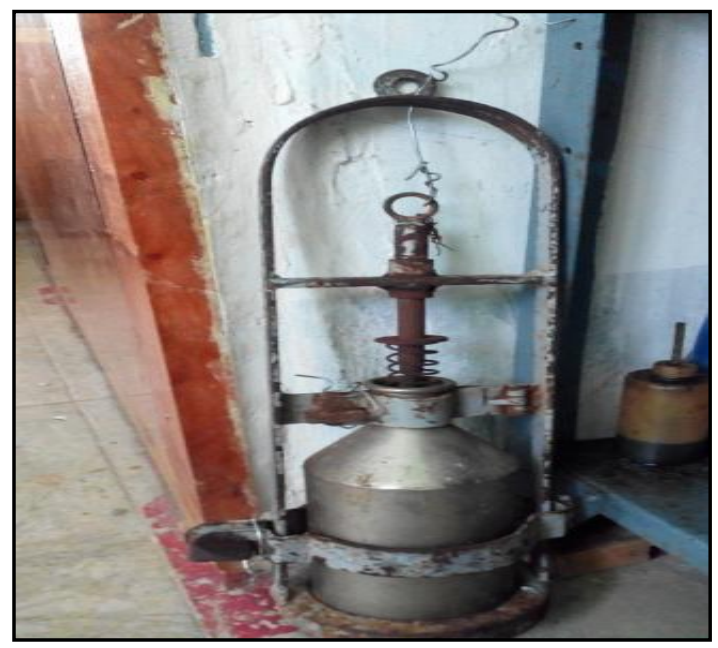

Figure 2: Punjab bottle sampler

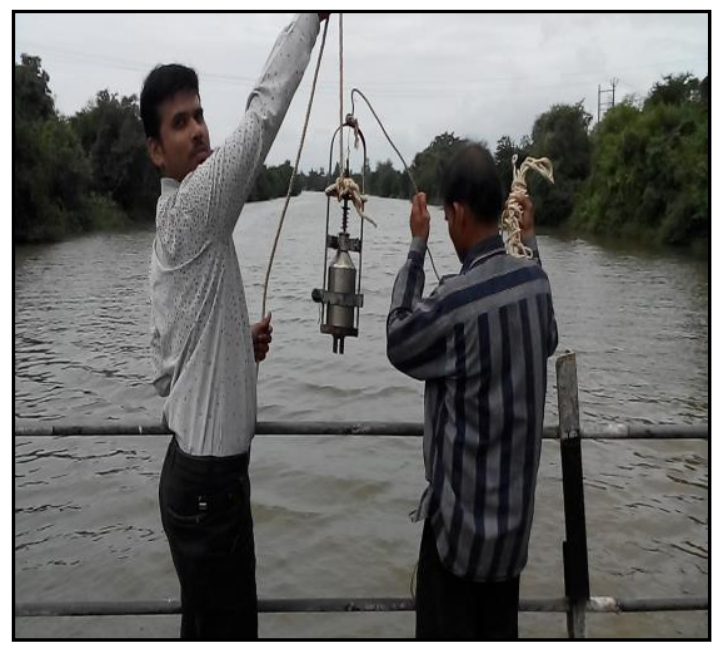

Figure 3: Collection of water sample 


\subsection{Water Discharge Measurement}

The current meter is used to measure the velocity of flow in the channel. The stainless steel carrying the cup wheel freely rotates in the bearing assembly. The magnet and reed switch assembly produces one pulse per rotation. The rotation of water current meter is sensed by sensor and gives pulsed output signal. The velocity of the flowing water is also measured at sampling depth. The current meter is allowed to move freely from the pulley and hang to the point of sampling depth. As the cup wheel rotated one revolution, the magnet and reed switch assembly produces one pulse and bulb on-off (blinking) is seen. The rotation for the fixed time is noted and the velocity is calculated directly in to metre per second. The current meter calibration chart is used to calculate the velocity in which the revolution and time in second is given. By using the interpolation work the velocity is directly calculated in metre per second. Also, the flow area is calculated by using the following equation:

$$
\mathbf{A}=\mathbf{B y}+\mathbf{m y}^{\mathbf{2}}
$$

Where, $\mathrm{A}=$ flow area in $\mathrm{m}^{2} ; \mathrm{B}=$ channel bottom width in $\mathrm{m} ; \mathrm{m}=$ channel side slope; and $\mathrm{y}=$ water depth in $\mathrm{m}$.

The average velocity and the average discharge are obtained through product of flow area along with average velocity.

\subsection{Calculation of Suspended Load}

The sample collected from all the sampling station is mixed in one water container to obtain the average sediment concentration over the channel cross-section. Test is carried out to find the medium size particles. In which one litre sample from the container is taken in the beaker and keep it for about few seconds to settle the medium size particle. Then after some amount of the top water is removed carefully from the beaker and the same amount of clear water is added and this procedure is to continue until the entire water is cleared. Then after the clear water is completely remove and let the medium size particle get oven dried in laboratory and measure the weight. The alum solution ranging from $2 \mathrm{ml}$ to $3 \mathrm{ml}$ depending upon the turbidity of water sample is to be added in the container and stirring it well in eight shapes by using glass rod for about few seconds. Keep the water sample for about 24 hour. Due to the mixture of alum solution in water sample the suspended solid particles gets settle down at the bottom of the container after 24 hour. The clear water is removed from the top carefully and remaining water is filter by using the whatman filter paper so that the suspended sediments are retained on the filter paper. Then the filter paper containing sediments is allowed to dry in oven at the temperature of 110 degree centigrade. The dry filter paper is removed from the oven and computation procedure is carried out.

\section{Result}

For the calculation of suspended sediment concentration the weight of laboratory oven dried filter paper without sediments and the weight of laboratory oven dried filter paper along with Sediments are recorded by using weigh machine. The weight of sediment is calculated by subtracting the weight of empty filter paper from the weight of oven-dried filter along with sediment. The average concentration of suspended sediment per one litre of sample for the entire cross-section of channel is measured by dividing the sediment weight by the number of sampling station. The following equation is used to calculate the suspended sediment transport rate.

$$
\mathrm{SST}=\mathrm{Q} \times \mathrm{Cs} \times 86.4
$$


Where, SST = suspended sediment transport rate in tonnes per day; $\mathrm{Q}=$ discharge in cumecs; $\mathrm{Cs}=$ suspended sediment concentration in gram per liter.

The above formula gives the suspended sediment transport rate in tones per day over the entire cross section of the channel. The data required for the suspended sediment concentration and suspended sediment transport rate are as shown in Table 1. The data required for lateral velocity distribution on selected canal section is as shown in Table 2 . The lateral velocity distribution for various discharges including maximum and minimum discharges are shown in figure 4, figure 5, figure 6 , and figure 7 .

\begin{tabular}{|c|c|c|c|c|c|c|c|c|c|c|c|c|c|}
\hline $\begin{array}{c}\text { Observation } \\
\text { No. }\end{array}$ & Date & $\begin{array}{c}\text { Sampling } \\
\text { Station }\end{array}$ & \begin{tabular}{|c|} 
Distance \\
From \\
H.R \\
$(\mathrm{km})$ \\
\end{tabular} & $\begin{array}{c}\text { Bottom } \\
\text { Width } \\
\text { (B) }\end{array}$ & $\begin{array}{c}\text { water } \\
\text { Depth } \\
\text { (y) }\end{array}$ & \begin{tabular}{|c|} 
water \\
width \\
$(\mathrm{T})$
\end{tabular} & $\begin{array}{c}\text { side } \\
\text { slope } \\
(\mathrm{m}: 1)\end{array}$ & $\begin{array}{l}\text { Flow } \\
\text { Area } \\
(\mathrm{m} 2)\end{array}$ & $\begin{array}{c}\text { Average } \\
\text { velocity } \\
(\mathrm{m} / \mathrm{s})\end{array}$ & \begin{tabular}{|c} 
Discharge \\
$(\mathrm{Q})$ \\
$(\mathrm{m} 3 / \mathrm{sec})$
\end{tabular} & $\begin{array}{c}\text { Average } \\
\text { Sediment } \\
\text { Concentration } \\
\text { (gram/litre) }\end{array}$ & \begin{tabular}{|c|} 
Average \\
Sediment \\
Concentration \\
(PPM) \\
\end{tabular} & $\begin{array}{c}\text { Sediment } \\
\text { Transport Rate } \\
\text { (Tonnes / Day) }\end{array}$ \\
\hline 1 & 6-Aug-16 & \multirow{4}{*}{$\begin{array}{l}\text { (Varjakhan) } \\
(10.00 \text { R.D) }\end{array}$} & \multirow{4}{*}{3.07} & \multirow{4}{*}{27.7368} & 1.500 & 32.2368 & \multirow{4}{*}{$1.5: 1$} & 44.9802 & 0.1511 & 6.7956 & 0.0298 & 29.8340 & 17.4968 \\
\hline 2 & 10-Aug-16 & & & & 1.410 & 32.1468 & & 42.0910 & 0.1423 & 5.9887 & 0.0138 & 13.8958 & 7.1405 \\
\hline 3 & 8-Sep-16 & & & & 3.300 & 37.6368 & & 107.866 & 0.6112 & 65.9301 & 0.0478 & 47.8000 & 272.2861 \\
\hline 4 & 10-Sep-16 & & & & 3.600 & 38.5368 & & 119.292 & 0.7133 & 85.0937 & 0.0900 & 90.0000 & 661.6887 \\
\hline
\end{tabular}

Table: 1 Data for Suspended Sediment Concentration

\begin{tabular}{|c|c|c|c|c|c|c|c|c|c|c|c|c|}
\hline \multirow{2}{*}{$\begin{array}{c}\text { Lateral } \\
\text { Station } \\
\text { No. }\end{array}$} & \multicolumn{3}{|c|}{ (6 Aug 2016) } & \multicolumn{3}{|c|}{ (10 Aug 2016) } & \multicolumn{3}{|c|}{ (8 Sep 2016) } & \multicolumn{3}{|c|}{ (10 Sep 2016) } \\
\hline & $\begin{array}{c}\text { Lateral } \\
\text { Distance }\end{array}$ & $\begin{array}{c}\text { Current } \\
\text { meter } \\
\text { revolution }\end{array}$ & $\begin{array}{c}\text { Point } \\
\text { Velocity } \\
\text { at 0.6d }\end{array}$ & $\begin{array}{c}\text { Lateral } \\
\text { Distance }\end{array}$ & $\begin{array}{c}\text { Current } \\
\text { meter } \\
\text { revolution }\end{array}$ & $\begin{array}{c}\text { Point } \\
\text { Velocity } \\
\text { at } 0.6 d\end{array}$ & $\begin{array}{c}\text { Lateral } \\
\text { Distance }\end{array}$ & $\begin{array}{c}\text { Current } \\
\text { meter } \\
\text { revolution }\end{array}$ & $\begin{array}{c}\text { Point } \\
\text { Velocity } \\
\text { at 0.6d }\end{array}$ & $\begin{array}{c}\text { Lateral } \\
\text { Distance }\end{array}$ & $\begin{array}{c}\text { Current } \\
\text { meter } \\
\text { revolution }\end{array}$ & $\begin{array}{c}\text { Point } \\
\text { Velocity } \\
\text { at 0.6d }\end{array}$ \\
\hline 1 & 9.00 & 13 & 0.1452 & 9.00 & 11 & 0.1208 & 6.60 & 44 & 0.5060 & 6.65 & 55 & 0.6340 \\
\hline 2 & 15.00 & 14 & 0.1570 & 15.00 & 14 & 0.1570 & 13.20 & 55 & 0.6340 & 13.30 & 60 & 0.6920 \\
\hline 3 & 19.00 & 16 & 0.1774 & 19.00 & 16 & 0.1774 & 19.80 & 61 & 0.7040 & 19.95 & 72 & 0.8396 \\
\hline 4 & 23.00 & 13 & 0.1452 & 23.00 & 13 & 0.1452 & 26.40 & 63 & 0.7289 & 26.60 & 68 & 0.7900 \\
\hline 5 & 28.00 & 12 & 0.1306 & 28.00 & 10 & 0.1110 & 33.00 & 42 & 0.4832 & 33.25 & 53 & 0.6110 \\
\hline
\end{tabular}

Table: 2 Data for Lateral Velocity Distribution on canal section

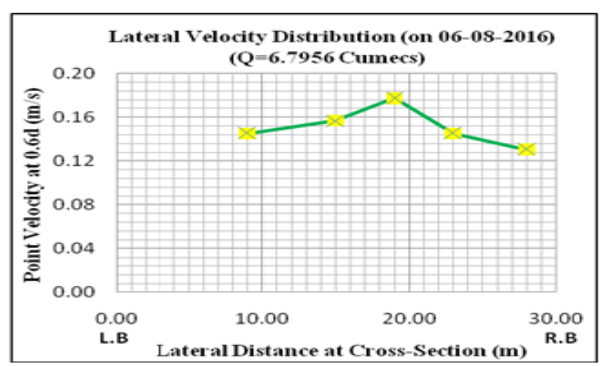

Fig. 4: Velocity Distribution for $Q=6.7956$ Cumecs

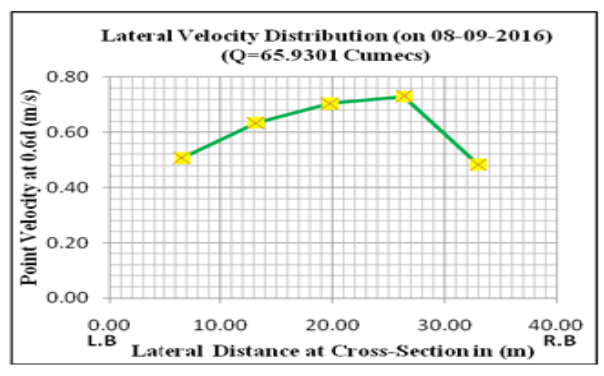

Fig. 6: Velocity Distribution for $Q=65.9301$ Cumecs

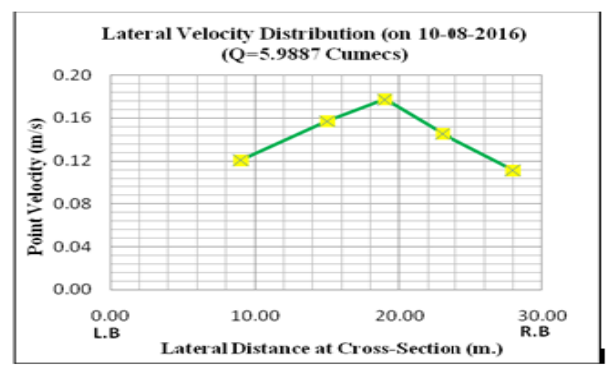

Fig. 5: Velocity Distribution for $Q=5.9387$ Cumecs

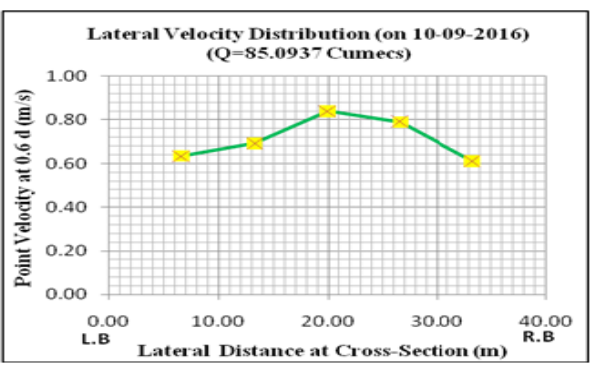

Fig. 7: Velocity Distribution for $Q=85.0937$ Cumecs 


\section{Conclusion}

The deposition of sediments in the canal reduces its carrying capacity. It is a practice in India to carry out desilting of canals at regular interval of time. This exercise requires huge cost. In the present study it has been found that the average suspended sediment concentration in ppm for minimum and maximum discharge condition of canal are 13.89 and 90.00 respectively. The field work was carried out during monsoon season. This concentration may decrease drastically, if it is carried out after monsoon period. From the present study, it can be concluded that to avoid silting of canal measures are required at the off taking points as well as at different locations along the length of the canal.

\section{Acknowledgement}

The authors appreciate the support from the surat irrigation circle and central water commission surat and their staff for better assistance with permission for experimental work and provision of required sampling instrument during the study period.

\section{References}

[1] Wren D. G., Barkdoll B. D., Kuhnle R. A., and Derrow R. W., "Field Techniques For Suspended-Sediment Measurement, "Journal of Hydraulic Engineering, Vol. 126, No. 2, pp. 97 104, February 2000.

[2] Kuhnle R. A., Wren D.G., "Lateral Variations in Suspended Sediment Concentration over Dunes," Journal of Hydraulic Engineering, Vol. 132, No. 12, pp. 1341-1346, December 2006.

[3] Wang Guangqian, Fu Xudong, Huang Yuefei, and Huang Gordon, "Analysis of Suspended Sediment Transport in Open-Channel Flows: Kinetic-Model-Based Simulation," Journal of Hydraulic Engineering, Vol. 134, No. 3, pp. 328-339, March 2008.

[4] Sedaei N.. Honarbakhsh A. and Mousavi F. "Suspended Sediment Formulae Evaluation, Using Field Evidence from Soolegan River," World Applied Sciences Journal 19 (4): 486-496, 2012.

[5] Khassaf S. I and Hassan A.A., "Suspended Sediment Rating Curve for Tigris River Upstream AL-AMARAH Barrage," International Journal of Advanced Research, vol.2 , Issue 5, pp. 624629, April 2014.

[6] Zhong Deyu, Wang Guangqian and Wu Baosheng, "Drift Velocity of Suspended Sediment in Turbulent Open Channel Flows," Journal of Hydraulic Engineering, Vol. 140, No. 1, pp. 35-47, January 2014.

[7] B.A.Kironoto and B.Yulistiyanto, "The Simplified of Suspended Sediment Measurement Method for Predicting Suspended Sediment Load as a Basic of Reservoir Capacity Design as Renewable Energy Resource,' International Journal of Renewable Energy Research, Vol.6, No.1, pp. 316322, March 2016 